\title{
Bilinguals' Use of English and Spanish Digitalk on Facebook Status Updates
}

\author{
Jacqueline Riley ${ }^{1}$ \\ ${ }^{1}$ Department of Teacher and Bilingual Education, Texas A\&M University, Kingsville, TX, USA \\ Correspondence: Jacqueline Riley, Department of Teacher and Bilingual Education, Texas A\&M University, \\ Kingsville, TX, USA. E-mail: jr100885@yahoo.com
}

Received: December 4, 2012 Accepted: December 19, 2012 Online Published: January 25, 2013

doi:10.5539/ijel.v3n1p1

URL: http://dx.doi.org/10.5539/ijel.v3n1p1

\begin{abstract}
The purpose of this multiple case study was to examine the ways in which six Hispanic, English-Spanish bilingual college students and college graduates used nonstandard writing (digitalk) to communicate through Facebook status updates and their reasons for doing so. The study consisted of three sources of data: Facebook status updates, one-on-one interview responses, and group interview responses. Based on an analysis of the data, it is probable that participants engaged in digitalk in both English and Spanish to achieve a variety of purposes. The similarities found between participants' English and Spanish digitalk may be indicative of participants' reliance on what Cummins (1991) refers to as Common Underlying Proficiencies in which languages rely on a single processing system.
\end{abstract}

Keywords: bilingual, digitalk, English, netspeak, Spanish

\section{Introduction}

Generally speaking, "digitalk" (Turner, 2011), and "digital communication" have been used to describe communication through digital technologies, which not only encompass computer-mediated communication, but other forms of technology such as text messaging; while "netspeak" refers to computer-mediated communication (Crystal, 2004). Digitalk can be found in emails (Volckaert-Legrier, Bernicot, \& Bert-Erboul, 2009), blogs (Kelly \& Safford, 2009; Stefanone \& Jang, 2008), instant messages (Jacobs, 2008; Ling \& Baron, 2010; Park, 2008), chatrooms (Merchant, 2001), social networks (Riley, in press; Carroll, 2008) and text messages (Delgado, 2009; Ling \& Baron, 2010). In some studies, researchers have explored monolingual digital language use, such as English digitalk (Baron, 2008; Ling \& Baron, 2010; Merchant, 2001; Turner, 2011) and Spanish digitalk (Delgado, 2009); however, relatively few studies (Riley, in press; Carroll, 2008) have focused on bilingual digitalk. Regardless of the language, such studies have found that online writers deviate from standard writing conventions, and instead, engage in distinct writing practices, which may include pictograms/logograms, initialisms, invented spelling, nonstandard capitalization, nonstandard punctuation and non-words. The following quotes were taken from an English-Spanish bilingual college student's Facebook status updates to exemplify some of the characteristics of digitalk in each language:

- $\quad$ On the road w/my fam...6 hrs to get to our destination...i think imguna take a nap

- Im freezing in here!!!!! And I think im gettin sick for the 3rd time this semester :S

- En la fila...se acabaron las vacaciones ninios!!!! :) los espero maniana en el salon de clases (In the line...the vacation has ended!!!!:) i expect you all tomorrow in the classroom)

\section{Review of the Literature}

Online writers' desires to display their identities, create a positive image of themselves, type faster, and emphasize different parts of the text may help to explain their use of digitalk. Identities are not manifested in isolation, but rather emerge in discourse (Ivanic, 1998); therefore people not only create their identities based on individuals that surround them in the real world, those with whom they communicate over the internet also influence their identities. In a technological era, people are able to change their identities according to the space they inhabit and become members of virtual, linguistic, and cultural communities. Furthermore, through collaborative online communication, learners may be able to form a collective identity (Spiliotopoulos and Carey, 2005). Identity can relate to the different discourses in which an individual participates. Hancock and Dunham 
(2001) indicated that children's digital communicative styles can also influence the ways in which identity is perceived. They concluded that as a result, children may adopt nonstandard written language use into their digital, communicative style, which may include emoticons, nonstandard capitalization and nonstandard punctuation (e.g., ellipses, hyphenation).

Turner (2011) speculated that using digitalk not only allowed those engaging in online communication to display their unique identities, but also enabled them to show their identities as members of a distinct community. By using initialisms, such as $\mathrm{nm}$ rather than the more formal not much, online writers were able to mark themselves as members of the digital language community (p. 268). Furthermore, within the confines of this digital language community, Turner (2011) suggested there may be additional communities. To exemplify this point, she highlighted how digitalk was used differently by those in an urban private, religious school community versus those in an urban public school. When individuals fail to conform to the guidelines, principles, and rules that govern an online community's manner of communication, they risk being excluded from the group (Crystal, 2001). Those who are able to understand text which deviates from standard writing become part of an in-group; while those who do not understand it comprise an out-group (Carroll, 2008). In short, the presence or absence of digitalk may be one way in which individuals show their membership in a given internet language community (Turner, 2011).

In an attempt to better understand why English-Spanish female bilingual users incorporated digitalk, Riley (in press) had four participants complete a survey in which they selected their reasons for engaging in nonstandard online writing practices. Similarly, her findings suggested that participants used digitalk to express their distinct personalities, since the identity that is presented online conveys a certain type of image. Furthermore, some users of computer-mediated communication are motivated by idealized self-presentation and wish to present themselves in a favorable way (Walther, 1996). In fact, it is not uncommon for internet users to be concerned with how they believe they are portrayed, particularly in environments where individuals' identities are not anonymous. For example, Facebook users may project the self that that they wish they were, rather than the self they actually are (Zhao, Grasmuck, \& Martin, 2008).

Merchant (2005) suggested that at times younger children believed that invented spelling and use of initialisms caused those with whom they communicated online to develop negative perceptions of them. One of Merchant's participants stated the following: "I was still really scared about spelling because they might be younger and they might know this really complicated spelling and they might think oohh that's a bit dumb" (p. 311). Other participants in his study also expressed their beliefs that people may judge them based on writing they used during an online conversation. One student shared his concern that incorrect spelling would cause others to view him as a stereotypical "country boy."

In addition to portraying a given identity, unconventional online writing may also be the result of one's desire to type faster. Technological forms of communication must be typed which takes more time than verbally conveying a message; therefore, users are encouraged to develop shortcuts and use fewer key strokes to more efficiently convey their messages (Crystal, 2008). As a result, writing is less formal, but more quickly produced. This may also be true for texters who use invented spelling in which they eliminate letters to make words smaller (Delgado, 2009). When Delgado (2009) asked one female participant why she chose to shorten words when texting in Spanish, she responded that she did so because she was lazy and did not want to have to write out the entire word. It is possible that users do not memorize how to reduce the letters in a given word, but rather engage in a creative process (Delgado, 2009). When it comes to punctuation, at times, it may be both easier and faster to use nonstandard punctuation. For instance, some individuals choose to omit punctuation marks such as apostrophes (Riley, in press). On certain phones, it may take as many as six key strokes to type an apostrophe. Moreover, the omission of an apostrophe is not likely to cause confusion. Furthermore, when the words Im, shes and theyre are placed in context, the recipient of the text will likely not have difficulty understanding the meaning (Crystal, 2008).

However, not all instances of nonstandard writing can simply be attributed to laziness. In some cases more effort is expended to use nonstandard writing than standard writing. For example, at one point a participant in Delgado's (2009) study used invented spelling which included repeated letters: "Q ondaniña? Como tassssssssssss?" (p. 51) (What's up girl? How are youuuuuuuuuuuu?). Delgado (2009) speculated that the repetition of letters may illustrate the author's intent to display greater intensity and emphasis. Riley's (in press) study supported Delgado's claim, finding that some English-Spanish bilingual females intentionally capitalized letters that were conventionally not capitalized to emphasize selected parts of the text. Crystal (2001) noted that the internet is not case sensitive, which motivates online writers to capitalize randomly or not capitalize at all. Messages written entirely in capital letters are considered to be shouted. When certain words are capitalized 
within a text, the writer is viewed as adding extra emphasis to selected parts of the text (Crystal, 2001).

The problem is that in most studies that have examined monolingual digitalk use (Baron, 2008; Ling \& Baron, 2010; Delgado, 2009) and bilingual digitalk use (Carroll, 2008; Riley, in press); it was left up to the researcher to speculate as to how and why the online writers engaged in digitalk, rather than allowing the writers themselves to reflect upon how and why they had used digitalk. Carroll (2008) and Riley (in press) studied small groups of English-Spanish bilinguals online writing practices. Based on the English and Spanish text from three Puerto Rican's MySpace profiles, Carroll (2008) speculated that the three individuals engaged in digitalk to portray themselves through their online profiles; however, he did not communicate with the users directly. By analyzing Facebook status updates and conducting a questionnaire, Riley (in press) examined the ways in which four Hispanic, female, English-Spanish bilinguals manipulated traditional writing to meet expectations, convey their personalities, type faster and emphasize text. Although Riley (in press) had the participants fill out a questionnaire, they provided general reasons for using digitalk, instead of reviewing their own text and explaining why they had used nonstandard writing in each specific instance. In contrast, in the present study, I used in-depth analysis of English-Spanish writers' text and interviews in which participants examined examples of their own online communications allowing them to explain why they used digitalk in each example. At this stage in the research, bilingual digitalk will be defined as communication through digital technologies, which not only encompass computer-mediated communication, but other forms of technology such as text messaging. Digitalk will include the following categories: pictograms/logograms, initialisms, nonstandard punctuation, nonstandard capitalization and non-words.

\subsection{Definitions}

Included below are terms which may be unfamiliar to readers.

\subsubsection{Emoticons}

"A sequential combination of keyboard characters designed to convey the emotion associated with a particular facial expression." (Crystal, 2004, p. 39).

\subsubsection{Logograms}

Logograms or logographs occur when a single graphic unit (i.e., letter, numeral, or typographic figure) is used to represent a word, part of a word, or a noise associated with the action (Crystal, 2008, pp. 37-38).

\subsubsection{Pictograms}

Meanings which are conveyed through the appearances of the emoticons themselves (Crystal, 2008, pp. 38-39).

\section{Methods}

\subsection{Participant Selection}

Six Hispanic English-Spanish bilinguals (three male and three female) between the ages of 18 and 24 participated in the study (See table 1). They were each given pseudonyms. All participants acquired Spanish as their first language and were born in Mexico. All participants were classified as intensive English-Spanish Facebook users, meaning that they displayed Facebook status updates written in one language (either English or Spanish) less than $85 \%$ of the time, and written in the other language/or a combination of the languages more than $15 \%$ of the time (Riley, in press). Based on participants' language use responses, participants' self-assessment of language dominance/mastery, and my observations of their Facebook language performance, all of the participants were considered to be relatively balanced bilinguals, meaning that they were "approximately fluent in two languages across various contexts" (Baker, 2006, p. 9). When the interviews were conducted, all of the bilinguals in this study were attending or had graduated from colleges in the United States.

To obtain participants, I used what Goetz and LeCompte (1984) referred to as network selection in which the sample is selected based on participant referrals. To gain referrals, I logged onto my Facebook account and found online friends who I knew spoke both English and Spanish. If these online Facebook friends met the criteria, they were asked to participate in the study and to refer any of their online friends, who may also be eligible to participate. These individuals were selected both for their accessibility and their ability to answer the following research questions which guided the study: 1) How do Hispanic, English-Spanish bilingual college students and college graduates use nonstandard text when communicating with online friends through Facebook status updates? and 2) What reasons do Hispanic, English-Spanish bilingual college students and college graduates give for using nonstandard text when communicating with online friends through Facebook status updates? In answering these questions, I focused on participants' use of pictograms/logograms, initialisms, invented spelling, nonstandard punctuation, nonstandard capitalization and non-words. 


\subsection{Phases of Data Collection}

Three phases of data collection were employed to examine how participants used nonstandard writing in Facebook status updates and their reasons for doing so. It was necessary to collect and analyze data in phases, because information that was revealed during each of the earlier stages influenced the questions that were asked during the later stages. In the first phase, I collected participants' status updates which allowed me to view the text of their online communications first hand. Since many Facebook users have privacy settings, which limit the public from viewing their status updates, pictures and other content, participants were required to add me as a Facebook friend thereby allowing me to view all their available content. Once able to access the necessary information, I logged on to my Facebook account, then viewed each participant's "wall." (Note 1) Facebook users' status updates were displayed on their wall.

I randomly selected 50 English status updates, 50 Spanish status updates and, depending on availability, up to five status updates which contained a mixture of English and Spanish. The selected status updates had been written within the past year old, but had not been written after participants were asked to take part in the study. Using a content analysis approach, the status updates were analyzed. During this phase of data analysis, the focus was on the linguistic and stylistic content of the status updates, rather than the messages that were conveyed. Based on a previous study (Riley, in press) and the literature I reviewed, participants' status updates were sorted into the following categories: pictograms/logograms (including emoticons, symbols, numbers and computer art), initialisms, invented spellings, nonstandard punctuation, nonstandard capitalization, and non-words. I then created a coding dictionary, which contained each of the categories and their definitions. Examples, when available, were also included in the coding dictionary.

To facilitate sorting the status updates into each of the six categories, I created a grid for each participant. The language of the status update and the six categories of digitalk were displayed in a row at the top of each page. The date of the post, as well as the text of each participant's randomly selected status updates were cut and pasted into a vertical column. Line by line, I read through each of the participant's status updates and wrote the examples of nonstandard writing under the appropriate categories. To make sure that the coding of the categories was reliable, in addition to myself, an individual whose native languages were English and Spanish coded a portion of the status updates. Consistent with Miles and Huberman's (1994) recommendation, the coder and I were in agreement at least $80 \%$ of the time. After all of the sampling units from the participants' status updates were sorted into their appropriate categories, the examples of nonstandard writing within each group were examined. Based on similarities, subcategories were created. I then created a new grid to compare digitalk use amongst participants. When possible, the number of instances in which each participant had used nonstandard writing versus standard writing was included.

In the second phase, during one-on-one Skype interviews, I asked participants questions about how and why they had used digitalk both in general and in specific status updates. Interviews were conducted within two months of participants agreeing to take part in the study. Through hour-long Skype interviews, in which audio but not video was required, I was able to hear participants' experiences and explanations of how and why they had produced the sample status updates. To ensure the questions from the interview guide were valid, prior to conducting any interviews, bilingual doctoral students from Texas A\&M-Kingsville participated in an online Skype audio focus group and provided me with feedback. Based on the focus group's comments, I modified my original questions. When it was time to conduct the interviews, with the permission of my participants, their calls were recorded. Consistent with Creswell (2007), I followed the interview protocol for asking questions and recording responses. After an initial question to break the ice, participants were asked a series of questions from the interview guide that reflected a narrowing of the research questions. Interviews followed a formal semi-structured format. The interview guides contained predetermined questions that were asked to all participants. Then, depending on participants' answers, I had the freedom to ask follow up and related questions.

In addition to the general questions, which appeared on the interview guide and were asked to all participants, participants were provided with written examples of their own status updates and were asked to explain their reasons for deviating from standard language. They were also asked if the nonstandard writing changed the meaning of their status updates and if it did in what ways it changed it. When possible, I selected several examples of status updates that illustrated nonstandard language use from each of the subcategories within the main categories (pictograms/logograms, initialisms, invented spelling, nonstandard punctuation, nonstandard punctuation, and non-words). When analyzing the interview transcripts I focused less on the words themselves and more on the meaning of what had been said. I transcribed each of the interviews in their entirety verbatim. As King and Horrocks (2010) suggested, I used three stages of thematic analysis: applying descriptive coding, applying interpretive coding, and defining overarching themes. 
The final phase of data collection consisted of group interview responses. The purpose of the group interview was twofold: 1) to follow up on any information revealed during the interviews that needed further explanation and elaboration and 2) to allow participants to clarify their thoughts through group discussion. Thus, the questions I asked were based on participants' status updates and responses from the previous interview. With participants' permission, the call was again recorded. After everyone had given their initial answer, participants were encouraged to comment on other's responses. Group interview data was analyzed in the same way one-on-one interviews were analyzed. The group interview was transcribed in its entirety verbatim. Then the codes that had been used in the individuals' interviews were applied to the group interview responses.

\section{Results and Discussion}

\subsection{Uses and Reasons for Nonstandard Writing}

The findings indicated that in both English and Spanish, each participant used digitalk in similar ways to achieve their goals. In using digitalk, the primary goal was for participants to convey the meaning of their written messages to their friends, while their secondary goals appeared to be to share their emotions, type faster, and highlight selected parts of the text. Thus, participants were more concerned with achieving these goals, rather than using standard writing. They cited three main reasons for utilizing digitalk. First, emoticons were used to show emotion. Second, participants added initialisms, shortened and clipped words, omitted necessary punctuation, and did not capitalize letters that required capitalization in an attempt to type faster and exert less effort. Third, participants repeated letters, spelled words as they were pronounced, added extra punctuation, and capitalized entire words/sentences to emphasize parts of the text and at times mimic spoken language.

\subsubsection{Pictograms/Logograms}

\subsubsection{Emoticons}

In both English and Spanish, participants added emoticons to show others how they felt about the status updates they had posted. The following status updates illustrate how Lydia used emoticons at the end of sentences in each language to reflect her feelings towards the information revealed in the text: "uugh my parents forgot to mention there was no hot water :/" and "aqii en mis brazoos puedes vivir:)" (here in my arms you can live :)). The emoticons ":)" and ":D" were used by all participants, while the emoticons "; ": ":P" and ":S" were used by five of the six Facebook writers. All emoticons appeared to transcend languages; in nearly all instances, respondents assigned a similar meaning to emoticons in each language in which they appeared. Regardless of if the status update was written in English or Spanish, emoticons were almost always placed before, after or within sentence breaks. In an examination of emoticon use on message boards, Provine, Spencer and Mandell (2010) found similar placements in $99 \%$ of cases. Lydia offered a practical reason for their placement, stating that if emoticons were placed prior to or within the sentence, her Facebook friends would not understand why the emoticon was used, because they had not yet read her status update.

Another important finding was that in each language most participants used emoticons frequently. In fact, 250 emoticons were added to the 622 status updates collected. This finding is contrary to Baron (2008) and Ling and Baron's (2010) findings that emoticons were rarely used in text messages and instant messages. These discrepancies may be attributed to the different forms of online communication and/or the participants themselves.

\subsubsection{Symbols and Numbers}

Each participant included numbers between three and nine times. Everyone except Isabel used numbers in both languages. Participants unanimously expressed that numbers were not written as words, because it was quicker and therefore easier, to type the numeral key than it was to type out the number's name in letters. When Daniel was asked why he chose numeric symbols, he asserted, "I'm lazy. It was simpler, faster." Just as participants explained that they had included numbers to help them type faster, they also affirmed the addition of symbols enabled them to save time as they wrote. With the exceptions of "\&", "(8)" and " $"$ " signs, different symbols were sometimes used in each language, which made it difficult to compare their role in English and Spanish status updates. The "\&" symbol was used in five of the six participants' status updates to type faster.

Like the "\&" sign, the "(8)" symbol was used by a majority of the participants. Everyone except Felix and Isabel included it in at least one of their status updates. Lydia and Daniel explained that on MSN messenger, when the "(8)" symbol was entered, the computer displayed a music note. Although the computer did not display the note when it was typed on Facebook, the symbol retained its meaning from MSN messenger and was used to show that the status update contained lyrics from a song. For instance, Daniel included the symbol to indicate that the following posts contained song lyrics: "And you just dont realize how much i love you (8)" and later, "Quiero ser 
yo el que despierte en ti un nuevo sentimiento (8)" (I want to be the one that awakens in you a new emotion (8)). Like the "(8)" symbol, the " $"$ " was also used by four of the participants. Those that included it in their status updates indicated that it could be used to represent the word "love" as in "I $\square$ Editing" (Elena) or a loving attitude towards the status update as in "Como extrañaba mi cama" (How I was missing my bed) (Isabel) or "Lunchh and moviies " (Lydia).

\subsubsection{Initialisms}

The extent to which initialisms (acronyms and alphabetisms) both specific and nonspecific to the internet varied from person to person. For instance, Daniel, Elena, and Lydia rarely included initialisms, while Marco added initialisms 30 times to his status updates. One key finding was that initialisms used offline (e.g., ESPN, EMT) were included occasionally, while those specific to the internet were added less frequently. This lends support to the findings of previous studies (Baron, 2008; Crystal 2008; Ling \& Baron, 2010; Riley, in press). The initialisms that were used the most were lol (laugh out loud), which was included in only three status updates and ily (I love you), that was added to just two status updates. Of the participants who did use them, each only did so one time. Crystal (2008) also noted that few intialisms were included with relative frequency. In addition to using intialisms, which were commonly used offline, Isabel and Marco tended to also write those that could generally be found on the internet. In English, Isabel's status updates contained lol (laugh out loud), bff (best friend forever), ily (I love you), and $w /$ (with), while in her Spanish posts she incorporated $d$ (de which is often used to mean of, from or show possession).

Interestingly, Spanish initialisms were almost never included and English initialisms were at times placed in Spanish status updates. Lydia suggested that Spanish speakers generally understood English initialisms. Carroll (2008) indicated that aspects of English pop culture have been incorporated into Spanish. Perhaps these English initialisms were borrowed from English internet culture and included in Spanish digitalk. Borrowing occurs when words are taken from one language or dialect and used in another (Crystal, 1980). Borrowing may result from speakers/writers of different languages coming into contact with one another. Thus, as Spanish writers inhabited the same virtual spaces online (e.g., Facebook, internet chatrooms) as English writers, they were exposed to and consequently adapted English initialisms.

Regardless of the language in which initialisms appeared, respondents often indicated that they had included them because initalisms were quicker and therefore easier than typing out the word(s) represented. Felix stated, "I wasn't going to write the whole word. I just wanted to make it short and simple." This finding seems to support Zipf's (1949) "Principle of Least Effort" which states that animals, people, and even well designed machines, will choose the path that requires the least amount of effort to achieve what they deem to be acceptable results. Nearly all the Facebook writers in this study suggested that their criteria for what was acceptable when writing status updates was different from what was considered to be acceptable in formal writing. Therefore, in order to meet the criteria for acceptable, participants adapted shortcuts, which allowed them to convey their message with the least amount of effort.

\subsubsection{Invented Spelling}

While initialisms shortened the number of letters in a word, repeating letters lengthened them. Every participant in this study had status updates in English and Spanish, which included repeated letters. Letters were sometimes repeated throughout the status update, as was evidenced when Lydia wrote, "Creatiive Modee On :)" and later "quieroo un perritoo :(" (I waant a little doogg). At other times, letters were only repeated in a single word, as exemplified in Daniel's status updates: "i need a research paper on prayer on schoool :(" and again "te amooo!!!" (I love youuu!!!).

Some participants claimed they repeated letters to mimic the way they would have said the words had they been speaking. Elena explained how adding extra letters allowed her writing to emulate speech: "I do a lot of my writings as if I was talking. So I think that if I would actually speak or talk and say these lines, I would emphasize that word." Crystal (2001) also concluded that writers may repeat letters in an attempt to imitate certain aspects of speech including pitch (intonation), speed, rhythm, loudness (stress) and pause. Delgado (2009) speculated that repetition of letters added greater emphasis and intensity to words in Spanish text messages.

In the present study, not only did participants indicate that they repeated letters to add emphasis and emulate speech, they also expressed that they had included alternate spellings to reflect how words were pronounced (e.g., gonna for going to and pa for para). For example in English Marco wrote, "When is this gonna stop! :("while in Spanish he wrote, "Rumboo pa Gtown!!" (Towards Gtown!!). When asked why he wrote the words in those examples, he answered, "That shows how I talk. Like how I would say it." Similarly, Riley (in press) also noticed bilingual writers added slang words to mimic speech in Facebook status updates, specifically, the word gonna. 
Merchant (2001) cited instances of words written as speech in English instant messaging conversations observing wot for what and woz for was.

Though infrequent, in each language, some participants employed invented spelling by reducing the number of letters in a word. This was accomplished by leaving out letters within a word and/or removing the end of a word. The following examples exhibit how Isabel incorporated fam for family and peli for pelicula (movie) in her status updates: "On the road w/my fam...." and "Ya kiero irme a mi ksita pa star entre las cobijas y ver una peli" (I want to go to my home already to be between the covers and to watch a movie).

Carroll's (2008) and Merchant's (2001) studies highlighted that shortened words were rarely included in online communication. Crystal (2011) also gives credence to this observation concluding that only a small number of text messages $(10 \%)$ contained shortened words. In the present study, when participants did remove letters from within a word, they generally omitted vowels. This observation finds support in Crystal's (2008) assertion that consonants carry more information that vowels. Participants expressed that despite the fact that they did not always include standard spelling of words, their online friends were able to understand their messages. Crystal (2008) attributed readers' abilities to understand such meanings based on the contexts in which they appear. This suggests that the Facebook writers in this study relied on their readers to deduce the words in their status updates.

While most forms of invented spelling were practiced in both languages. There were instances in which participants used alternative spellings of words that were specific to each language. For example, with the exception of Felix, all participants used unconventional spellings in Spanish (e.g., $k$ or $q$ ) to represent $q u$, as did digital writers from previous studies (Carroll, 2008; Delgado 2009; Riley, in press). Participants suggested that they did so to type faster, again using less effort, and to mimic the writing styles of their online friends.

\subsubsection{Nonstandard Punctuation}

One significant finding of this study was that participants sometimes left out necessary punctuation. Several of the bilingual writers explained the reason they did not include punctuation and/or accents was not because they had chosen to not use standard punctuation, but rather the result of failing to choose to use standard punctuation. Participants also expressed that they did not do so because they were able to expend less effort and type faster. The decreased effort involved in omitting necessary punctuation again finds support in Zipf's (1949) "Principle of Least Effort." Crystal (2008) explained that when typing from certain cellphones, it can take many keystrokes to insert some punctuation symbols, and thus it is both easier and faster to leave out such punctuation. Moreover, Pargman and Palmer (2004) indicated that writers' choices are influenced by how easy or difficult it is to include Latin characters from their computers.

When punctuation was included, at times, it was unconventional. Repeated punctuation was used by all of the participants. In both English and Spanish, all participants used repeated periods in places which traditionally necessitated a comma or period. While some used a standard ellipsis which included three dots (...), others used two or four periods. Each individual was generally consistent with the number of periods he or she added throughout status updates. Felix's status updates illustrated how he used ellipses to create a pause after and in between his thoughts: "Apparently Im not very good at dodging raindrops..." and "Benditas sean las bebidas energizantes... por fin en casita :D" (Blessed are the energy drinks... finally at home :D). Turner (2011) also witnessed online writers using ellipses in this unique way in English instant messages. Like the individuals in the present study, Crystal (2001) and Carroll (2008) suggested that ellipses were used to express pauses.

Additionally, although each of the six bilingual Facebook writers used a single exclamation mark the majority of the time, each also included repeated exclamation marks in both English and Spanish status updates. They explained that the purpose of doing so was to emphasize or intensify the emotion reflected in their status updates. Crystal (2001) mentioned that exaggerated punctuation can be added to a sentence to show emphasis and attitude In many cases, the emotion was excitement or happiness, as exemplified in Elena's status updates: "P.S Tomorrow is December!! :D" and "Bueno, que orgullo es decir "le voy al Guadalajara"!! :D" (Well, how proud to say "I am for Guadalajara!! :D").

\subsubsection{Nonstandard Capitalization}

Just as participants at times did not include correct punctuation, in some instances, they also did not correctly capitalize the first words of sentences, proper nouns and the word "I". The frequencies in which they did not capitalize these letters varied from occasionally to frequently. While Lydia and Isabel sometimes did not capitalize the first letters of sentences, Elena, Daniel, Felix, and Marco often included required capitalization. The Facebook writers in this study generally stated that they did so to save time and because they were not 
concerned about using proper capitalization. Thus, again less effort was required to not capitalize letters that required punctuation, than to do so, unless participants' devices automatically capitalized certain words, in which case, less effort would be needed to accept the phone's correction, than to change it.

Carroll (2008) observed a similar lack of capitalization in bilingual MySpace users' profiles. Crystal (2001) attributed online writer's lack of necessary capitalization to the fact that the internet is not case sensitive. Conversely, to give a selected word or words additional emphasis, the Facebook writers would capitalize all the letters within that word or several words. Lydia exemplified how capitalizing NOT in English and YO (I) in Spanish highlighted their importance within their respective sentences. She wrote, "There is only one way to find out whether there is life after death.. and I am NOT that curious :P" and "Casi nunca pierdo.. pero cuando llega a pasar YO si se perder :)" (I almost never lose..but when it happens I know how to lose:)). When asked why she chose to capitalize selected words and not others, she asserted, "I guess it's how I would say it. It's like I'm NOT that curious. That would be the word I would stress the most."

In each language, Felix's status updates exhibited how by emphasizing certain phrases he was able to show his excitement as he cheered for sports teams: "A hacerse grandes! VAMOS MEXICOOOOO!!!" (Make it grand! LET'S GO MEXICOOOOO!!!) and "Get some turkev. Get some smashed potatoes. Or get some cold beers. But most of all.. GET YOUR HORNS UP!" Crystal (2001) supported the participants' explanations by confirming that when certain words are capitalized within a text, the writer is viewed as emphasizing or shouting out that part of the text.

\subsubsection{Non-Words}

All participants occasionally included non-words that represented laughter. While English posts included variations of haha and hehe, Spanish status updates sometimes included variations of jaja and jeje. Depending on the author, the number of syllables varied from just one, $h a$, to many, hahahaha and from jajato jajaja. While haha was found in both English and Spanish status updates, jaja and jeje were only included in Spanish ones. Like emoticons, letters which indicated laughter were written before, after or within sentence breaks. Respondents explained they added such words to show that they thought what they had written was funny, or to demonstrate that they were joking, or having a good time. In the following status update, Marco included haha to demonstrate a joking attitude, "I was doing homework online but the page froze and closed! Pfff.. Ima take it as a sign for me to stop doing homework. hahaha." He demonstrated a similar attitude with his use of jajaja in his Spanish status update : "Ya tengo dos horas despierto.. Riendome de Uds. jajaja" (I've been awake for two hours..Laughing at You all. hahaha).

In addition to writing letters that emulated laughter, Daniel, Isabel, Lydia and Marco also included other words to convey sounds. For instance, Isabel and Lydia both added $a w w w$ to their status updates. Lydia wrote, "Awwww se suspenden dos baby showerss los bebes tenian prisaa :/“ (Awwww, two baby showerss were postponed the babies were in a huurry :/ )." She communicated why she had used the sound: "it was like kind of cute like aww. To express emotions." In some ways, this is similar to Crystal's (2001) observations of members of chatgroups and virtual worlds inclusion of non-words (e.g., aaaiiieee and yayyyyyyy) to reflect emotions of horror, shock and the like. In both cases, online writers deviated from using actual words, and instead wrote letters that mimicked the sounds they wished to convey.

\subsection{Attitudes Towards Using Digitalk on Facebook}

In addition to exploring the specific reasons participants gave for using digitalk, a general examination of participants' attitudes towards using nonstandard language in status updates also helped to explain why they deviated from standard writing. All participants expressed that they knew that they used a different writing style on Facebook than they used in instances that required formal writing (e.g., school assignments and resumes). Respondents suggested that they had chosen to deviate from conventional writing styles because Facebook was a place in which it was acceptable to use nonstandard language. In the following quote, Elena explains the differences between formal writing and her writing on Facebook, while also indicating that her writing will not be judged like a school assignment: "In academic papers or resumes or stuff like that, I'm very concerned with gramatic errors, or the content, or the vocabulary that's being used and conveying the idea that I want and on Facebook, I'm not as concerned about these aspects and I know like I'm not being graded or something like that. So, I don't really care if it's seen bad or wrong."

\subsection{Transferability of Digitalk Skills between English and Spanish}

Just as being able to follow guidelines for formal writing is considered to be a skill, the ability to convert thoughts into digital may also be skill. Through the application of this skill, online writers may have been able to 
express their emotions, type faster, add emphasis, emulate speech and convey their messages. Unlike many other skills, such a skill is not taught in schools, and is generally not learned in books. In contrast to formal writing, nonstandard writing does not follow prescriptive rules, but rather is developed through written online communication. As participants had conversations with online friends, they may have developed the knowledge and skills necessary to engage in digitalk conversations. For each category of digitalk it is possible they learned the following: 1) what types were used, 2) how the application of each type can alter the meaning of the message, and 3) how each type can be applied to achieve various purposes.

Participants may have been more likely to transfer literacy skills between languages when the languages themselves were similar (Bialystok, Luk, \& Kwan, 2005; Deacon, Wade-Woolley, \& Kirby, 2009). English and Spanish do share many commonalities; this is especially true when it comes to the application of digitalk in each language. Thus, it is probable that for participants who learned Spanish and English digitalk sequentially, the online writing skills acquired in Spanish were transferred to English. As is true for the transfer of many language skills, one must know the language well enough to use it in the appropriate context.

The idea that nonstandard online writing is a skill, which can be learned in one language and applied to another, may be suggestive of what Cummins (1991) refers to as Common Underlying Proficiencies in which languages operate within a central processing system and skills and knowledge can be transferred between languages. In order for this transfer to be possible, individuals must have developed sufficient abilities in each language. The theory of Common Underlying Proficiencies may predict that since participants relied on the same central processing system, they would produce similar text in each language. In fact this did occur; analysis of each participant's status updates indicated that pictograms/logograms, initialisms, invented spelling, nonstandard capitalization, nonstandard punctuation and non-words were employed in comparable ways in each language.

De Vel, Anderson, Corney, and Mohay (2001) noted that authors leave their "digital fingerprint" on their emails, by employing specific structural characteristics and linguistics patterns. The findings in this study suggested that the ways and frequencies in which participants used digitalk in status updates may also serve as authors' "digital fingerprints." By this I mean that each participant made stylistic choices (e.g., which emoticons to add, which types of invented spellings to use), that differentiated their online writing from others. Orebaugh and Allnut (2009) mentioned that characteristics of digitalk (e.g., emoticons and initialisms) provided substantial clues to instant messages' authors. In the present study, these digitalk idiosyncrasies were not limited to English or Spanish, but instead transcended languages, thereby resulting in similar use of digitalk in each language. Furthermore, when participants were asked why they had deviated from conventional stylistic writing practices as they related to each of the categories of nonstandard writing, each generally gave the same explanation for doing so in English as in Spanish.

One may argue that these categories of digitalk are the same in both English and Spanish, and therefore, participants did not rely on common underlying proficiencies, but rather separately learned how to employ the online writing styles of each language. In response to this observation, I would point out that while I included a summary of the commonalities between participants, within each of these categories there was variation. By looking at differences between the ways in which participants used nonstandard language, the relationship between each individual's use in English and Spanish is highlighted. For example, frequencies in which participants included each type of digitalk ranged from often to almost never. In each language, these frequencies were relatively consistent for each participant across a given subcategory.

\section{Summary and Conclusion}

In both English and Spanish, all the participants in this study included pictograms/logograms, initialisms, invented spelling, nonstandard capitalization, nonstandard punctuation and non-words. Although the frequencies in which participants employed each category and subcategory of digitalk varied from person to person, an individual's frequencies in each of the subcategories were generally relatively consistent across languages. Just as participants' application of digitalk in each language was similar, so too were the reasons they gave for using each type. The Facebook writers preferred to deviate from the conventions of standard writing to achieve a variety of purposes (i.e., conveying emotions, typing faster, emphasizing selected parts of the text and mimicking speech). Thus, in each language, the bilinguals in this study valued writing's function (i.e., to achieve specific purposes) over adhering to standard writing practices. Furthermore, most participants attributed their decision to not use formal writing to their belief that it was acceptable to use digitalk when writing Facebook status updates.

The data suggests that the ability to convert thoughts into status updates can be viewed as a skill which can be learned in English, Spanish or simultaneously in both languages. Once learned, the ability can be transferred to a second language where it is applied within the constraints of that language. It is probable that in English and 
Spanish, digitalk was used in similar ways and for similar purposes, thus facilitating the transfer of digitalk between languages. The ability to transfer a skill from one language to another is indicative of Cummins' (1991) Common Underlying Proficiencies. This theory would likely predict that individuals would use digitalk in similar ways in both English and Spanish. This in fact did occur as participants employed comparable styles of digitalk, for similar reasons and in similar frequencies.

\section{Limitations and Suggestions for Future Research}

Based on the findings in this multiple case study, I was able to develop inferences about the six participants' nonstandard Facebook writing; however, these inferences may not be true for bilingual writers outside of this study. This is likely due, in part, to the fact that my sample was obtained through network selection, in which I asked people I knew to refer eligible participants. Many of the members were linked to one another through network connections and shared some commonalities (e.g., their languages, age ranges, levels of education). I encourage future researchers to replicate the present study using larger and more diverse participants. By including a more heterogeneous population, researchers will be able to draw conclusions that can be generalized beyond the participants in this study.

For instance, when examining the digitalk produced by individuals of various ages, researchers may observe how writing styles reflective of participants' generations may manifest themselves. Just as peoples' ages may influence the types of digitalk used, individuals' languages and places of origin may also contribute to their styles of digitalk. Languages and dialects spoken in specific communities are likely reflected in writer's digitalk. The order in which individuals acquire languages may also influence their acquisition of digitalk. The participants in this study learned Spanish prior to English. Researchers may wish to conduct a similar study with bilinguals who acquired English first or simultaneously acquired both languages. Such research may help to illustrate implications of learning a given language prior to another.

Additionally, the data indicated participants' abilities in English and Spanish were relatively balanced; however, in future studies, researchers may wish to use standardized assessments to ascertain participants' reading, writing, speaking and listening proficiencies in each language. The results of these tests would likely create a more complete picture of participants' language abilities as they relate to online writing. For instance, based on participants' language abilities, researchers could also determine if the cognitive processes required to convert thoughts to status updates is different for those who are just beginning to acquire a second language and are not yet fluent in that language. Although this study did examine commonalities and differences between the ways in which participants used nonstandard language, it did not directly explore the online dynamic between participants and how these dynamics may have influenced individuals' writing styles. Therefore, researchers may wish to focus on how online writers within a connected social network affect one another's use of formal or informal writing.

Finally, the digitalk coding dictionary from this study may be used by future researchers as a resource for those analyzing online conversations in English and Spanish. Based on analysis of additional online communications, researchers can add to, omit and modify the existing definitions to reflect their own findings. The coding dictionary is likely to undergo further changes based on the population and type of online communication being studied.

\section{References}

Abram, C., \& Pearlman, L. (2008). Facebook for dummies. Hoboken, NJ: Wiley.

Baker, C. (2006). Foundations of bilingual education and bilingualism (4th ed.). Clevedon: Multilingual Matters.

Baron, N. (2008). Language in an online and mobile world. Oxford: University.

Bialystok, E., Luk, G., \& Kwan, E. (2005). Bilingualism, biliteracy, and learning to read: Interaction among languages and writing systems. Scientific Studies of Reading, 9(1), 43-61. http://dx.doi.org/10.1207/s1532799xssr0901_4

Carroll, K. S. (2008). Puerto Rican language use on MySpace.com. CENTRO Journal, 20(1), 97-111.

Creswell, J. W. (2007). Qualitative inquiry and research design: Choosing among the five approaches (2nd ed.). Thousand Oaks: Sage.

Crystal, D. (1980). A first dictionary of linguistics and phonetics. Boulder, CO: Westview.

Crystal, D. (2001). Language and the internet. Cambridge: Cambridge University. 
Crystal, D. (2004). A glossary of netspeak and textspeak. Edinburg: Edinburg University.

Crystal, D. (2008). Txting: The gr 8 db8. Oxford: Oxford University.

Crystal, D. (2011). Internet linguistics: A student guide. London: Routledge.

Cummins, J. (1991). Interdependence of first- and second language proficiency in bilingual children. In E. Bialystok (Ed.), Language processing in bilingual children (pp. 70-89). New York: Cambridge University.

De Vel, O., Anderson, A., Corney, M., \& Mohay, G. (2001). Mining e-mail content for author identificationforensics. SIGMOD Record, 30(4), 55-64. http://dx.doi.org/10.1145/604264.604272

Deacon, S. H., Wade-Woolley, L., \& Kirby, J. R. (2009). Flexibility in young second language learners: Examining the language specificity of orthographic processing. Journal of Research in Reading, 32(2), 215-229. http://dx.doi.org/10.1111/j.1467-9817.2009.01392.x

Delgado, G. O. (2009). Msjetxt: Un evento social. Lectura y Vida, Diciembre, 44-53.

Goetz, J. P., \& LeCompte, M. D. (1994). Ethnography and qualitative design in educational research. Orlando, FL: Academic Press.

Hancock, J. T., \& Dunham, P. J. (2001). Impression formation in computer-mediated communication revisited: An Analysis of the Breadth and Intensity of Impressions. Communication Research, 28(3), 325-347. http://dx.doi.org/10.1177/009365001028003004

Ivanic, R. (1998). Writing and identity: The discoursal construction of identity. Philadelphia: John Benjamins.

Jacobs, G. E. (2008). We learn what we do: Developing a repertoire of writing practices in an instant messaging world. Journal of Adolescent and Adult Literacy, 52(3), 203-211. http://dx.doi.org/10.1598/JAAL.52.3.33

Kelly, A., \& Safford, K. (2009). Does teaching complex sentences have to be complicated? Lessons from children's online writing. Literacy, 43(3), 118-122. http://dx.doi.org/10.1111/j.1741-4369.2009.00501.x

King, N., \& Horrocks, C. (2010). Interviews in qualitative research. London: Sage.

Kraynak, J., \& Belicove, M. E. (2010). The complete idiot's guide to Facebook. New York: Alpha.

Ling, R., \& Baron, N. S. (2010). Text messaging and IM: Linguistic comparison of American college data. Journal of Language and Social Psychology, 26(3), 291-298. http://dx.doi.org/10.1177/0261927X06303480

Merchant, G. (2001). Teenagers in cyberspace: An investigation of language use and language change in internet chatrooms. Journal of Research in Reading, 24(3), 293-306. http://dx.doi.org/10.1111/1467-9817.00150

Merchant, G. (2005). Electronic involvement: Identity performance in children's informal digitalwriting. Discourse: Studies in the Cultural Politics of Education, 26(3), 301-314. http://dx.doi.org/10.1080/01596300500199940

Miles, M. B., \& Huberman, A. M. (1994). Qualitative data analysis: A sourcebook of new methods. Thousand Oaks, CA: Sage.

Orebaugh, A., \& Allnutt, J. (2009). Classification of instant messaging communications of forensics analysis. The International Journal of Forensic Computer Science, 1, 22-28. Retrieved from http://www.ijofcs.org/V04N1PP02\%2\%20Classification\%20of\%20Instant\%20Messaging\%20Communicati ons.pdf

Pargman, D., \& Palmer, J. (2004). Linguistic standardization on the internet. Proceedings of the 4th International Conference on Cultural Attitudes Towards Technology and Communication, 385-388.

Park, J. (2008). Linguistic politeness and face-work in computer mediated communication, part 2: An application of the theoretical framework. Journal of the American Society for Information Science and Technology, 59(14), 2199-2209. http://dx.doi.org/10.1002/asi.20926

Provine, R. R., Spencer, R. J., \& Mandell, D. L. (2010). Emotional expression online: Emoticons punctuate website text messages. Journal of Language and Social Psychology, 26(3), 299-307. http://dx.doi.org/10.1177/0261927X06303481

Riley, J. (in press). Influences of Facebook on English-Spanish bilinguals' writing.Journal ofBorder Educational Research.

Spiliotopoulus, V., \& Carey, S. (2005). Investigating the role of identity in writing using electronic bulletin boards. The Canadian Modern Language Review, 62(1), 87-109. http://dx.doi.org/10.1353/cml.2005.0046 
Stefanone, M. A., \& Jang, C.-Y. (2008). Writing for friends and family: The interpersonal nature of blogs. $\begin{array}{llll}\text { Journal of Computer-Mediated } & \text { Communication, } & \text { 13(1), }\end{array}$ http://dx.doi.org/10.1111/j.1083-6101.2007.00389.x

Turner, K. H. (2011). Digitalk: Community, convention, and self-expression. National Society for the Study of Education, 10(1), 263-282.

Volckaert-Legrier, O., Bernicot, J., \& Bert-Erboul, A. (2009). Electronic mail, a new written-language registrar: A study with French-speaking adolescents. The British Psychological Society, 27, 163-181.

Walther, J. B. (1996). Computer-mediated communication: Impersonal, interpersonal, and hyperpersonalinteraction. $\quad$ Communication $\quad$ Research, 23, 1-43. http://dx.doi.org/10.1177/009365096023001001

Zhao, S., Grasmuck, S., \& Martin, J. (2008). Identity construction on Facebook: Digital empowerment in anchored relationships. Computers in Human Behavior, 24, 1816-1836. http://dx.doi.org/10.1016/j.chb.2008.02.012

Zipf, G. K. (1949). Human behavior and the principle of least-effort: An introduction to human ecology. Cambridge, MA: Addison-Wesley.

Note

Note 1 . The wall is a term used to describe the place in which, among other things, users are able to view the status updates of their Facebook friends.

\section{Appendices}

\section{Appendix I}

Participants' background information

\begin{tabular}{|c|c|c|c|c|c|c|}
\hline Participant & Age & $\begin{array}{c}\text { Age of } \\
\text { Arrival to } \\
\text { U.S. }\end{array}$ & $\begin{array}{l}\text { ESL/bilingual } \\
\text { education } \\
\text { (grade) }\end{array}$ & $\begin{array}{c}\text { Age of first } \\
\text { online comm.* }\end{array}$ & $\begin{array}{l}\text { Age of first } \\
\text { Facebook } \\
\text { account** }\end{array}$ & $\begin{array}{c}\text { Dominant } \\
\text { language(s) }\end{array}$ \\
\hline Elena & 18 & 11 & $\begin{array}{l}\text { Bilingual } \\
\text { education } \\
\text { (K-4) }\end{array}$ & 10 & 14 & $\begin{array}{l}\text { English and } \\
\text { Spanish }\end{array}$ \\
\hline Marco & 19 & 6 & $\begin{array}{l}\text { Bilingual } \\
\text { education } \\
(1-2)\end{array}$ & 7 & 16 & $\begin{array}{l}\text { English and } \\
\text { Spanish }\end{array}$ \\
\hline Lydia & 19 & 9 & $\begin{array}{l}\text { Spanish } \\
\text { support } \\
(4)^{* * *}\end{array}$ & 10 & 15 & $\begin{array}{c}\text { English and } \\
\text { Spanish }\end{array}$ \\
\hline Daniel & 19 & 14 & $\begin{array}{c}\text { Bilingual } \\
\text { education } \\
\mathrm{K}-3,6-8\end{array}$ & $7-8$ & 16 & $\begin{array}{c}\text { English and } \\
\text { Spanish }\end{array}$ \\
\hline Felix & 20 & 12 & $\begin{array}{l}\text { ESL } \\
(7)\end{array}$ & 11 & 15 & $\begin{array}{l}\text { Slightly } \\
\text { dominant in } \\
\text { Spanish }\end{array}$ \\
\hline Isabel & 24 & 15 & $\begin{array}{l}\text { ESL } \\
(9)\end{array}$ & 12 & 22 & $\begin{array}{c}\text { English and } \\
\text { Spanish }\end{array}$ \\
\hline
\end{tabular}

$*$ Comm. $=$ communication

** All participants indicated that they began to communicate in English and Spanish on Facebook at relatively the same time.

*** Lydia was enrolled in an English only classroom, but received Spanish instruction from her teacher. 


\section{Appendix II}

\section{Interview Guide}

Participant,

Please honestly and thoroughly reflect on the following questions as they relate to the status updates you write on Facebook. Your answers will be used to help the researcher understand bilingual students' online cognitive processes. Write notes to help you answer the questions. You will be discussing your responses with the researcher during your scheduled interview time. You may use extra paper if necessary. The researcher may ask you additional questions based on your responses and status updates. Please allow one hour for your interview. Thank you for your participation.

Scheduled interview date and time:

\section{Part 1. Background Information}

1. How old are you?

2. Do you consider English, Spanish, or both languages dominant? Why?

3. At what age did you learn English?

4. At what age did you learn Spanish?

5. In what language(s) were you formally educated? Please explain.

6. In what contexts did you speak/hear English?

7. In what contexts did you read/write English?

8. In what contexts did you speak/hear Spanish?

9. In what contexts did you read/write Spanish?

10. At what age and in what language(s) did you begin to use Facebook?

11. How did you develop your written English online communications skills (e.g., How did you know how to write on Facebook in English)?

12. How did you develop your written Spanish online communications skills (e.g., How did you know how to write on Facebook in Spanish)?

Part 2. Examples from Your Status Updates*

Please write your reason for using nonstandard writing in the examples provided. You may select different reasons for using each type of digitalk in each language. You may also select multiple reasons for each category.

A. To communicate my thoughts and/or emotions better

B. I am not concerned with how others perceive my online writing

C. I know those reading what I have written do not care if it is written using standard language

D. I do not know how to use standard writing when communicating online

E. To type faster

F. To reflect my personality

G. To emphasize parts of the text

H. Other

\begin{tabular}{|c|c|c|c|}
\hline Digitalk Category & $\begin{array}{l}\text { Examples from your } \\
\text { English FB status updates }\end{array}$ & $\begin{array}{l}\text { Examples from your Spanish FB } \\
\text { status updates }\end{array}$ & $\begin{array}{l}\text { Reason(s) for } \\
\text { digitalk in each } \\
\text { language and } \\
\text { comments }\end{array}$ \\
\hline \multicolumn{4}{|l|}{$\begin{array}{l}\text { I. PICTOGRAMS/ } \\
\text { LOGOGRAMS }\end{array}$} \\
\hline $\begin{array}{l}\text { A. Emoticons (smiley } \\
\text { faces/computer art) }\end{array}$ & $\begin{array}{l}\text { October 13, } 2011 \\
\text { No work today at my } \\
\text { second job :) I think im } \\
\text { guna take a long nap after } \\
\text { school :) }\end{array}$ & $\begin{array}{l}\text { August } 21,2011 \\
\text { En la fila...se acabaron las vacaciones } \\
\text { ninios!!!! :) los espero maniana en el } \\
\text { salon de clases }\end{array}$ & \\
\hline A2 & $\begin{array}{l}\text { October } 13.2011 \\
\text { Im freezing in here!!!!! } \\
\text { And I think im gettin sick } \\
\text { for the 3rd time this } \\
\text { semester :S }\end{array}$ & $\begin{array}{l}\text { November } 29.2011 \\
\text { aue disque me vine a estudiar } \\
\text { tranquilamente aca a la casa para mi } \\
\text { examen de maniana v me traen de } \\
\text { chacha :S y \$) jajaja }\end{array}$ & \\
\hline
\end{tabular}

* This section of the interview guide contains a sample of how participants' status updates were used; however, in the actual interview guides many examples were included within each category. 


\section{Appendix III}

\section{Participants' Nonstandard Language Use in Status Updates}

\begin{tabular}{|c|c|c|c|c|c|c|c|}
\hline Category & Daniel & Elena & Felix & Isabel & Lydia & Marco & Totals \\
\hline \multicolumn{8}{|l|}{$\begin{array}{l}\text { I. Pictograms \& } \\
\text { Logograms }\end{array}$} \\
\hline \multicolumn{8}{|l|}{ A. Emoticons } \\
\hline English & 19 & 19 & 10 & 32 & 29 & 27 & 136 \\
\hline Spanish & 21 & 19 & 7 & 27 & 31 & 9 & 114 \\
\hline Both & 1 & 3 & 0 & 2 & 3 & 1 & 10 \\
\hline Total & 41 & 41 & 17 & 61 & 63 & 37 & 250 \\
\hline \multicolumn{8}{|l|}{ B. Symbols } \\
\hline English & 6 & 3 & 4 & 5 & 10 & 1 & 29 \\
\hline Spanish & 2 & 8 & 0 & 5 & 15 & 5 & 35 \\
\hline Both & 0 & 0 & 0 & 0 & 1 & 0 & 1 \\
\hline Total & 8 & 11 & 4 & 10 & 26 & 6 & 65 \\
\hline \multicolumn{8}{|l|}{ C. Numbers } \\
\hline English & 3 & 2 & 4 & 9 & 2 & 2 & 22 \\
\hline Spanish & 3 & 4 & 4 & 0 & 1 & 2 & 14 \\
\hline Total & 6 & 6 & 8 & 9 & 3 & 4 & 36 \\
\hline \multicolumn{8}{|l|}{ D. Computer Art } \\
\hline Spanish & 0 & 0 & 0 & 1 & 0 & 1 & 2 \\
\hline \multicolumn{8}{|c|}{ Pictograms \& Logograms' } \\
\hline \multicolumn{8}{|c|}{ Totals by Language } \\
\hline English & 28 & 24 & 18 & 46 & 41 & 30 & 187 \\
\hline Spanish & 26 & 31 & 11 & 33 & 47 & 17 & 165 \\
\hline Both & 1 & 3 & 0 & 2 & 4 & 1 & 11 \\
\hline $\begin{array}{l}\text { All Pictograms and } \\
\text { Logograms }\end{array}$ & 55 & 58 & 29 & 81 & 92 & 48 & 353 \\
\hline \multicolumn{8}{|l|}{ II. Initialisms } \\
\hline \multicolumn{8}{|c|}{ A. Non-internet Specific } \\
\hline English & 2 & 2 & 6 & 4 & 0 & 17 & 31 \\
\hline Spanish & 1 & 0 & 1 & 0 & 0 & 3 & 5 \\
\hline Total & 3 & 2 & 7 & 4 & 0 & 20 & 36 \\
\hline \multicolumn{8}{|l|}{ B. Internet Specific } \\
\hline English & 0 & 0 & 0 & 3 & 2 & 3 & 8 \\
\hline Spanish & 0 & 0 & 0 & 3 & 1 & 6 & 10 \\
\hline Both & 0 & 0 & 0 & 2 & 0 & 1 & 3 \\
\hline Total & 0 & 0 & 0 & 8 & 3 & 10 & 21 \\
\hline \multicolumn{8}{|l|}{ Initialisms' Totals by } \\
\hline English & 2 & 2 & 6 & 7 & 2 & 20 & 39 \\
\hline Spanish & 1 & 0 & 1 & 3 & 1 & 9 & 15 \\
\hline Both & 0 & 0 & 0 & 2 & 0 & 1 & 3 \\
\hline All Initialisms & 3 & 2 & 7 & 12 & 3 & 30 & 57 \\
\hline
\end{tabular}




\begin{tabular}{|c|c|c|c|c|c|c|c|}
\hline Category & Daniel & Elena & Felix & Isabel & Lydia & Marco & Totals \\
\hline \multicolumn{8}{|c|}{ III. Invented Spelling } \\
\hline \multicolumn{8}{|c|}{ A. Repeated Letters } \\
\hline English & 2 & 1 & 1 & 5 & 14 & 2 & 25 \\
\hline Spanish & 4 & 6 & 14 & 4 & 14 & 16 & 58 \\
\hline Both & 0 & 0 & 0 & 0 & 2 & 0 & 2 \\
\hline Total & 6 & 7 & 15 & 9 & 30 & 18 & 85 \\
\hline \multicolumn{8}{|c|}{ B. Written as Pronounced } \\
\hline English & 1 & 3 & 1 & 5 & 3 & 2 & 15 \\
\hline Spanish & 0 & 0 & 0 & 11 & 5 & 35 & 51 \\
\hline Total & 1 & 3 & 1 & 16 & 8 & 37 & 66 \\
\hline \multicolumn{8}{|c|}{ C. Letters Omitted } \\
\hline \multicolumn{8}{|c|}{$\begin{array}{l}\text { 1. Letters Omitted } \\
\text { within Word }\end{array}$} \\
\hline English & 1 & 0 & 0 & 8 & 0 & 11 & 20 \\
\hline Spanish & 0 & 0 & 0 & 4 & 1 & 15 & 20 \\
\hline Both & 0 & 0 & 0 & 6 & 0 & 0 & 6 \\
\hline Total & 1 & 0 & 0 & 18 & 1 & 26 & 46 \\
\hline \multicolumn{8}{|c|}{ 2. Clipped Word } \\
\hline English & 0 & 1 & 1 & 3 & 1 & 2 & 8 \\
\hline Spanish & 0 & 1 & 1 & 5 & 1 & 0 & 8 \\
\hline Both & 0 & 0 & 0 & 2 & 0 & 0 & 2 \\
\hline Total & 0 & 2 & 2 & 10 & 2 & 2 & 18 \\
\hline \multicolumn{8}{|c|}{ D. Possible Typo } \\
\hline English & 1 & 2 & 3 & 0 & 2 & 1 & 9 \\
\hline Spanish & 0 & 0 & 2 & 1 & 0 & 2 & 5 \\
\hline Total & 1 & 2 & 5 & 1 & 2 & 3 & 14 \\
\hline \multicolumn{8}{|c|}{ E. Omitted Space } \\
\hline English & 0 & 0 & 0 & 0 & 0 & 1 & 1 \\
\hline Spanish & 0 & 2 & 1 & 4 & 1 & 1 & 9 \\
\hline Both & 0 & 0 & 0 & 1 & 0 & 0 & 1 \\
\hline Total & 0 & 2 & 1 & 5 & 1 & 2 & 11 \\
\hline \multicolumn{8}{|c|}{ F. Added Space } \\
\hline
\end{tabular}




\begin{tabular}{llllllll}
\hline Category & Daniel & Elena & Felix & Isabel & Lydia & Marco & Totals \\
\hline $\begin{array}{l}\text { G. English Letter } \\
\text { Substitutions }\end{array}$ & & & & & & & \\
& & & & & & & \\
$\quad \begin{array}{l}\text { 1. } u \text { for } y \text { ou } \\
\text { 2. } \text { for } \text { and }\end{array}$ & 0 & 0 & 1 & 2 & 0 & 1 & 4 \\
3. $r$ for are & 0 & 0 & 0 & 1 & 0 & 1 & 2 \\
$\quad$ 4. ur for yourlyou're & 0 & 0 & 0 & 1 & 0 & 0 & 1 \\
$\quad$ Total & 0 & 0 & 1 & 5 & 0 & 2 & 8
\end{tabular}

H. Spanish Spelling

Substitutions

$\begin{array}{llllllll}\text { 1. q for qu } & 0 & 6 & 0 & 0 & 28 & 0 & 34 \\ \text { 2. k forqu/ que/qué } & 7 & 0 & 0 & 25 & 0 & 0 & 31 \\ \text { 3. ni used for ñ } & 0 & 0 & 0 & 9 & 6 & 0 & 15 \\ \text { 4. s for z } & 0 & 1 & 0 & 0 & 3 & 1 & 5 \\ \text { 5. x for por } & 0 & 1 & 0 & 2 & 0 & 2 & 5 \\ \text { 6. v for b } & 0 & 0 & 0 & 0 & 2 & 2 & 4 \\ \text { 7. z for s } & 0 & 0 & 0 & 3 & 1 & 0 & 4 \\ \text { 8. k for c } & 0 & 0 & 0 & 2 & 1 & 0 & 3 \\ \text { 9. s for c } & 0 & 0 & 0 & 0 & 0 & 2 & 2 \\ \text { 10. j for g } & 0 & 0 & 1 & 0 & 0 & 0 & 1 \\ \text { 11. z for c } & 1 & 0 & 0 & 0 & 0 & 0 & 1 \\ \text { Total } & 8 & 8 & 1 & 41 & 41 & 7 & 105\end{array}$

Invented Spellings' Totals

by Language

English

Both

All Invented Spelling

$\begin{array}{lllllll}5 & 7 & 7 & 26 & 20 & 21 & 86 \\ 12 & 17 & 19 & 73 & 65 & 76 & 262 \\ 0 & 0 & 0 & 9 & 2 & 0 & 11 \\ 17 & 24 & 26 & 108 & 87 & 97 & 359\end{array}$

IV. Nonstandard

Punctuation

A. Missing Punctuation

1. Missing End

Punctuation

English

Spanish

Both

$\begin{array}{lll}5 & 14 & 16\end{array}$

16
10

30

23

4

92

Total

2. Missing

Quotation Marks

English

Spanish

$\begin{array}{ll}16 & 0 \\ 13 & 0 \\ 1 & 0 \\ 30 & 0\end{array}$

1
0
0
1

1
3
0
4

11
5
0
16

1




\begin{tabular}{|c|c|c|c|c|c|c|c|}
\hline Category & Daniel & Elena & Felix & Isabel & Lydia & Marco & Totals \\
\hline \multicolumn{8}{|c|}{$\begin{array}{l}\text { 3. Missing English } \\
\text { Punctuation }\end{array}$} \\
\hline \multicolumn{8}{|l|}{ a. Missing } \\
\hline English & 4 & 2 & 5 & 16 & 12 & 5 & 44 \\
\hline Both & 0 & 0 & 0 & 0 & 0 & 1 & 1 \\
\hline Total & 4 & 2 & 5 & 16 & 12 & 6 & 45 \\
\hline \multicolumn{8}{|c|}{ a. Missing Accent } \\
\hline Spanish & 21 & 20 & 27 & 50 & 52 & 20 & 190 \\
\hline Both & 2 & 2 & 0 & 5 & 2 & 1 & 12 \\
\hline Total & 23 & 22 & 27 & 55 & 54 & 21 & 202 \\
\hline \multicolumn{8}{|c|}{ b. Missing “ $i$ ” } \\
\hline Spanish & 8 & 19 & 20 & 10 & 5 & 20 & 82 \\
\hline Both & 1 & 0 & 1 & 2 & 0 & 0 & 4 \\
\hline Total & 9 & 19 & 21 & 12 & 5 & 20 & 86 \\
\hline \multicolumn{8}{|c|}{ c. Missing “ $¿$ ” } \\
\hline Spanish & 0 & 5 & 1 & 2 & 2 & 4 & 14 \\
\hline Both & 0 & 0 & 0 & 1 & 0 & 0 & 1 \\
\hline Total & 0 & 5 & 1 & 3 & 2 & 4 & 15 \\
\hline $\begin{array}{l}\text { d. Missing } \\
\text { Spanish }\end{array}$ & \multicolumn{6}{|c|}{ d. Missing Tilde } & 4 \\
\hline \multicolumn{8}{|c|}{ B. Repeated Punctuation } \\
\hline \multicolumn{8}{|l|}{ 1. Periods } \\
\hline English & 14 & 6 & 20 & 43 & 37 & 15 & 135 \\
\hline Spanish & 10 & 14 & 7 & 35 & 58 & 20 & 144 \\
\hline Both & 0 & 1 & 0 & 9 & 1 & 4 & 15 \\
\hline Total & 24 & 21 & 27 & 87 & 96 & 39 & 294 \\
\hline \multicolumn{8}{|c|}{ 2. Exclamation } \\
\hline English & 1 & 4 & 6 & 3 & 4 & 6 & 24 \\
\hline Spanish & 1 & 9 & 14 & 1 & 4 & 7 & 36 \\
\hline Both & 1 & 0 & 0 & 2 & 0 & 3 & 6 \\
\hline Total & 3 & 13 & 20 & 6 & 8 & 16 & 66 \\
\hline \multicolumn{8}{|c|}{ 3. Question Marks } \\
\hline English & 0 & 1 & 1 & 1 & 1 & 0 & 4 \\
\hline Spanish & 0 & 0 & 1 & 1 & 1 & 0 & 3 \\
\hline Both & 0 & 0 & 0 & 0 & 0 & 0 & 0 \\
\hline Total & 0 & 1 & 2 & 2 & 2 & 0 & 7 \\
\hline \multicolumn{8}{|c|}{ Nonstandard Punctuation } \\
\hline English & 40 & 27 & 49 & 94 & 88 & 30 & 328 \\
\hline Spanish & 66 & 72 & 84 & 130 & 159 & 74 & 585 \\
\hline Both & 8 & 5 & 3 & 21 & 4 & 9 & 50 \\
\hline $\begin{array}{l}\text { All Nonstandard } \\
\text { Punctuation }\end{array}$ & 114 & 104 & 136 & 245 & 200 & 113 & 963 \\
\hline
\end{tabular}




\begin{tabular}{|c|c|c|c|c|c|c|c|}
\hline Category & Daniel & Elena & Felix & Isabel & Lydia & Marco & Totals \\
\hline \multicolumn{8}{|c|}{$\begin{array}{l}\text { V. Nonstandard } \\
\text { Capitalization }\end{array}$} \\
\hline \multicolumn{8}{|c|}{ A. Missing Capitalization } \\
\hline \multicolumn{8}{|c|}{$\begin{array}{l}\text { 1. First Letter of } \\
\text { Sentence }\end{array}$} \\
\hline English & 0 & 2 & 1 & 27 & 16 & 4 & 50 \\
\hline Spanish & 4 & 6 & 0 & 20 & 34 & 9 & 73 \\
\hline Both & 2 & 0 & 0 & 3 & 0 & 0 & 5 \\
\hline Total & 6 & 8 & 1 & 50 & 50 & 13 & 128 \\
\hline \multicolumn{8}{|c|}{$\begin{array}{l}\text { 2. Proper Noun \& } \\
\text { Other }\end{array}$} \\
\hline English & 1 & 6 & 4 & 14 & 2 & 0 & 27 \\
\hline Spanish & 2 & 5 & 0 & 26 & 4 & 4 & 41 \\
\hline Both & 1 & 0 & 0 & 3 & 0 & 0 & 4 \\
\hline Total & 4 & 11 & 4 & 43 & 6 & 4 & 72 \\
\hline \multicolumn{8}{|c|}{ 3. Word "I" } \\
\hline English & 5 & 2 & 2 & 8 & 7 & 7 & 31 \\
\hline Both & 1 & 0 & 0 & 0 & 0 & 1 & 2 \\
\hline Total & 6 & 2 & 2 & 8 & 7 & 8 & 33 \\
\hline \multicolumn{2}{|c|}{ Capitalization } & & & & & & \\
\hline \multicolumn{8}{|c|}{ 1. Single Letter } \\
\hline English & 7 & 1 & 0 & 1 & 8 & 3 & 20 \\
\hline Spanish & 4 & 1 & 11 & 1 & 5 & 5 & 27 \\
\hline Both & 0 & 1 & 0 & 0 & 0 & 0 & 1 \\
\hline Total & 11 & 3 & 11 & 2 & 13 & 8 & 48 \\
\hline \multicolumn{8}{|l|}{ 2. Word } \\
\hline English & 2 & 3 & 3 & 3 & 7 & 2 & 20 \\
\hline Spanish & 3 & 1 & 4 & 5 & 5 & 1 & 19 \\
\hline Total & 5 & 4 & 7 & 8 & 12 & 3 & 39 \\
\hline $\begin{array}{l}\text { Nonstandard } \\
\text { Capitalizatio } \\
\text { Language }\end{array}$ & \multicolumn{7}{|c|}{ Capitalizations' Totals by } \\
\hline English & 15 & 14 & 10 & 53 & 40 & 16 & 148 \\
\hline Spanish & 13 & 13 & 15 & 52 & 48 & 19 & 160 \\
\hline Both & 4 & 1 & 0 & 6 & 0 & 1 & 12 \\
\hline \multicolumn{8}{|c|}{ VI. Non-words } \\
\hline A. Sounds & & & & & & & \\
\hline English & 4 & 0 & 1 & 12 & 2 & 2 & 21 \\
\hline Spanish & 1 & 0 & 5 & 12 & 8 & 10 & 36 \\
\hline Both & 0 & 0 & 0 & 8 & 2 & 1 & 11 \\
\hline Total & 5 & 0 & 6 & 32 & 12 & 13 & 68 \\
\hline
\end{tabular}

